\title{
A bad shortcut: partial anomalous pulmonary venous return
}

\author{
Gautam V Ramani, ${ }^{1}$ Seth J Kligerman, ${ }^{2}$ Robert M Reed ${ }^{3}$
}

'Department of Cardiology, University of Maryland, Baltimore, Maryland, USA ${ }^{2}$ Department of Radiology, University of Maryland, Baltimore, Maryland, USA

${ }^{3}$ Department of Pulmonary and Critical Care Medicine University of Maryland, Baltimore, Maryland, USA

\section{Correspondence to}

Dr Robert Michael Reed, rreed@medicine.umaryland.edu

Accepted 19 March 2014

\section{DESCRIPTION}

A woman in her 70s with a longstanding history of 'heart murmur' presented with worsening shortness of breath. Transthoracic echocardiogram demonstrated a severely dilated and dysfunctional right ventricle (RV), severe pulmonary hypertension and a dilated coronary sinus (video 1). A CT scan demonstrated a large sinus venosus-type atrial septal defect with partial anomalous pulmonary venous return (PAPVR) involving veins draining the right-upper and right-middle lobes into the superior vena cava (SVC; figure 1 and video 2 ).

Right heart catheterisation demonstrated flowmediated pulmonary hypertension, with saturations rising from $52 \%$ to $99 \%$ when measured high versus low in the SVC, consistent with PAPVR. Her pulmonary to systemic blood flow ratio (Qp:Qs)

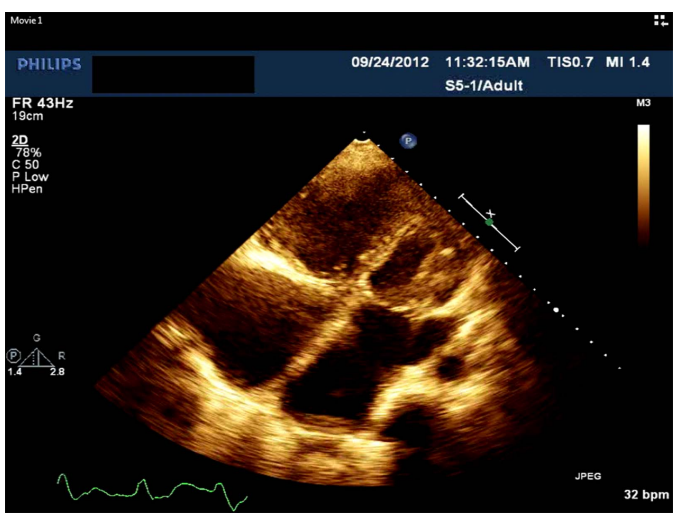

Video 1 Transthoracic Echocardiogram. was calculated as 2.7:1 (normal 1:1), with a normal right atrial pressure of $7 \mathrm{~mm} \mathrm{Hg}$, elevated mean pulmonary artery pressure of $40 \mathrm{~mm} \mathrm{Hg}$, and a normal pulmonary artery wedge pressure of $13 \mathrm{~mm} \mathrm{Hg}$. Cardiac output was markedly elevated at $12 \mathrm{~L} / \mathrm{min}$ (normal $\sim 5 \mathrm{~L} / \mathrm{min}$ ).

Despite the presence of severe pulmonary hypertension and the echocardiographic finding of severe RV dysfunction, her pulmonary vascular resistance (PVR) was less than 3 Wood units and her right atrial pressure was normal, suggesting a compensated physiological state. The patient was felt to be a good surgical candidate due to the relatively low PVR and high Qp:QS. She declined surgical intervention citing her age as the main factor and expired a few months later from her cardiac condition.

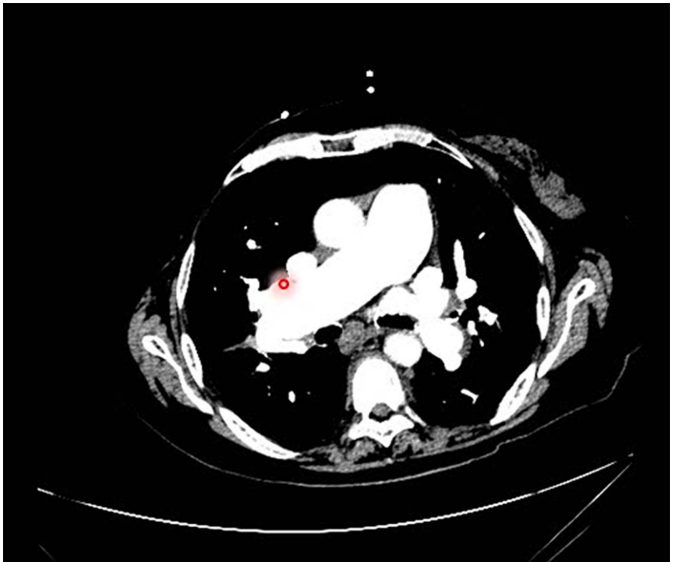

Video 2 CT Review of Anatomy.

Figure 1 Three-dimensional CT reconstruction of vascular anatomy (SVC, superior vena cava; PV, pulmonary venous).

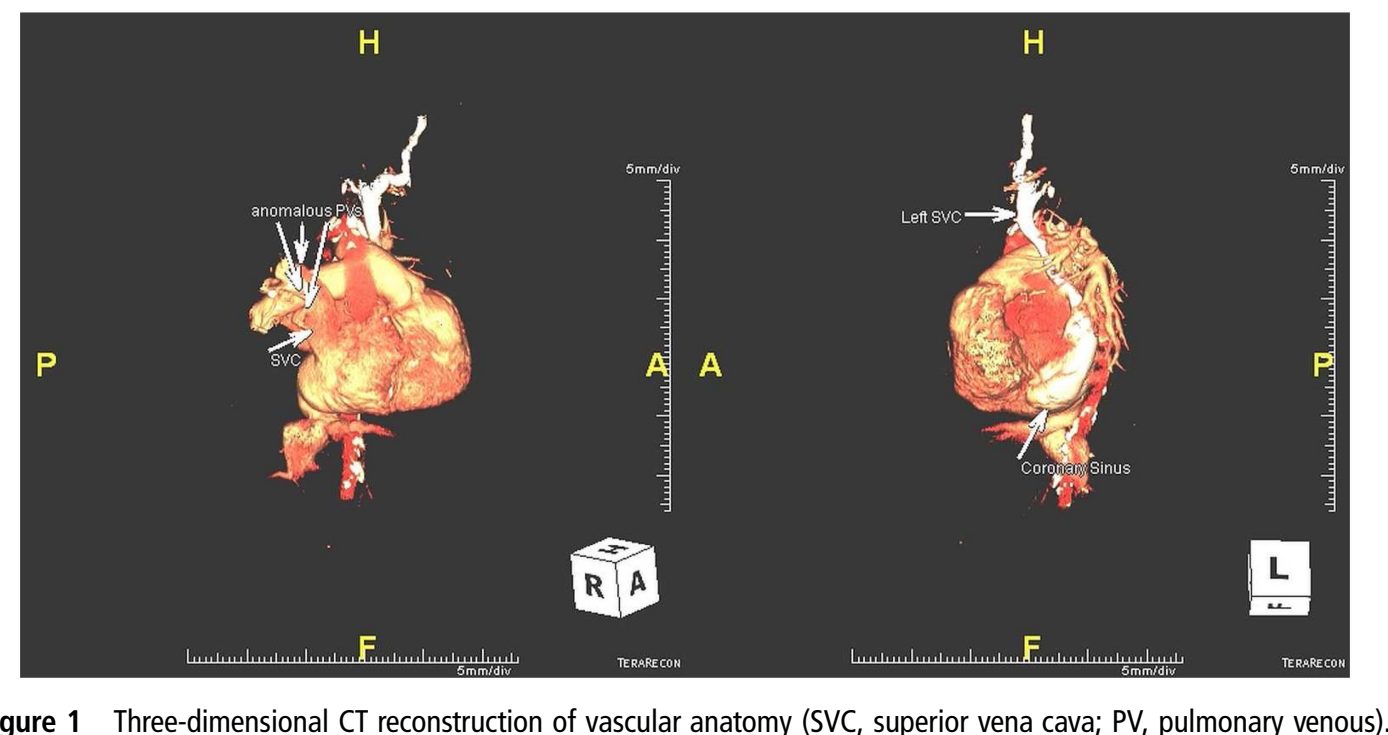




\section{Learning points}

- Although the shunt fraction is a risk factor for the development of pulmonary vascular disease, this case demonstrates that even patients with longstanding high-flow shunts may not develop pulmonary arterial hypertension.

- The prevalence of partial anomalous pulmonary venous return is most often reported between $0.1 \%$ and $0.7 \%$, though this may represent an underestimate, as many patients may be completely asymptomatic. ${ }^{12}$

- The magnitude of the left-to-right shunt, the presence of symptoms and the pulmonary vascular resistance all factor into decisions regarding treatment. ${ }^{3}$
Acknowledgements $\mathrm{Dr}$ Reed is supported in part by the Flight Attendants Medical Research Institute.

Contributors All authors contributed to researching the case and the condition, and writing and revising the manuscript.

Competing interests None.

Patient consent None.

Provenance and peer review Not commissioned; externally peer reviewed.

\section{REFERENCES}

1 Healey JE. An anatomic survey of anomalous pulmonary veins: their clinical significance. J Thoracic Surg 1952;23:433-44.

2 Ho ML, Bhalla $S$, Bierhals A, et al. MDCT of partial anomalous pulmonary venous return (PAPVR) in adults. J Thorac Imaging 2009;24:88-95.

3 Gustafson RA, Warden HE, Murray GF, et al. Partial anomalous pulmonary venous connection to the right side of the heart. J Thorac Cardiovasc Surg 1989;98(5 Pt 2): 861-8.

Copyright 2014 BMJ Publishing Group. All rights reserved. For permission to reuse any of this content visit

http://group.bmj.com/group/rights-licensing/permissions.

BMJ Case Report Fellows may re-use this article for personal use and teaching without any further permission.

Become a Fellow of BMJ Case Reports today and you can:

- Submit as many cases as you like

- Enjoy fast sympathetic peer review and rapid publication of accepted articles

- Access all the published articles

- Re-use any of the published material for personal use and teaching without further permission

For information on Institutional Fellowships contact consortiasales@bmjgroup.com

Visit casereports.bmj.com for more articles like this and to become a Fellow 